\title{
In-situ alloying of AlSi10Mg+Si using Selective Laser Melting to control the Coefficient of Thermal Expansion
}

\author{
Theresa Hanemann ${ }^{\mathrm{a}, *}$, Luke N. Carter ${ }^{\mathrm{b}}$, Moritz Habschied ${ }^{\mathrm{a}}$, Nicholas J.E. Adkins ${ }^{\mathrm{b}}$, \\ Moataz M. Attallah ${ }^{\mathrm{b}}$, Martin Heilmaier ${ }^{\mathrm{a}}$ \\ ${ }^{a}$ Institute for Applied Materials (IAM-WK), Karlsruhe Institute of Technology (KIT), Engelbert-Arnold-Str. \\ 4, D-76131 Karlsruhe, Germany \\ ${ }^{b}$ School of Metallurgy and Materials, University of Birmingham, Birmingham B15 2TT, UK
}

\begin{abstract}
Selective Laser Melting (SLM) was investigated as new processing route for strongly hypereutectic AlSi alloys for thermal management applications in space industry. Processing conditions, microstructure and thermal expansion behavior were analyzed for AlSi10Mg+Si alloys with $25 \mathrm{wt} \%$ and $50 \mathrm{wt} \%$ Si fabricated by in-situ SLM of powder mixtures. For both Si compositions parts with densities $\geq 99 \%$ could be achieved using laser power $\geq 275 \mathrm{~W}$ and scan speeds $\geq 1500 \mathrm{~mm} / \mathrm{s}$ for the alloy containing $25 \mathrm{wt} \%$ $\mathrm{Si}$ and laser power of $400 \mathrm{~W}$ and scan speeds $\geq 1500 \mathrm{~mm} / \mathrm{s}$ for the alloy containing $50 \mathrm{wt} \% \mathrm{Si}$. Considerable refinement of primary and eutectic Si was achieved for both Si compositions due to the high cooling rates of SLM. The mean particle size for the coarse primary Si of the $50 \mathrm{wt} \% \mathrm{Si}$ containing alloy was below $10 \mu \mathrm{m}$. Additionally, unmolten Si powder particles were observed. Measurements of the coefficient of thermal expansion (CTE) showed the tailorability of CTE with adjustment of Si content. A decrease in CTE of $43 \%$ compared to pure $\mathrm{Al}$ was achieved at a total Si content of $50 \mathrm{wt} \%$. Experimental data was close to model calculations based on the rule of mixture and the Turner model depending on the different microstructures of the two alloy compositions.
\end{abstract}

Keywords: Hypereutectic Al-Si alloy, Selective Laser Melting, Thermal expansion, Microstructure

\section{Introduction}

Aluminum alloys with high $\mathrm{Si}$ content exhibit favorable properties such as low weight, good wear resistance and low coefficient of thermal expansion (CTE) [1, 2]. The latter is of special interest for thermal management and packaging applications due to the requirement of dimensional stability during temperature changes. Additionally, in aerospace and space industry component weight is a critical factor and therefore

${ }^{*}$ Corresponding author. Present adress: Institute for Technical Physics, Karlsruhe Institute of Technology (KIT), Hermann-von-Helmholtz-Platz 1, D-76344 Eggenstein-Leopoldshafen, Germany

Email address: theresa.hanemann@kit.edu (Theresa Hanemann) 
packaging materials with low density are preferred for such applications. Aluminum combines low density and high thermal conductivity, which makes it attractive as thermal managing material in aerospace and space applications. However, Aluminum has a high CTE compared to circuit board materials $(\mathrm{GaAs}, \mathrm{Si})$. To reduce the CTE of pure Aluminum filler materials such as $\mathrm{SiC}$ or AlN can be added [3]. A different approach is the use of hypereutectic Al-Si alloys from the binary Al-Si eutectic system as $\mathrm{Si}$ reduces the CTE of Aluminum without compromising the low density. Thus, with deliberate adjustment of Si content the CTE of Al-Si alloys can be tailored to fit specific application requirements [4]. However, the cast microstructure of these alloys usually consists of coarse primary Si particles and acicular Si within the eutectic, which results in poor mechanical properties [4]. Besides, special manufacturing techniques, such as spray forming or PM processing have to be applied in order to produce complex parts $[1,2,5,6]$.

Therefore, Selective Laser Melting (SLM) is investigated as alternative processing technique. SLM is an Additive Manufacturing (AM) powder bed process permitting the production of complex three dimensional components by selective and layerwise melting of a metal powder [7]. Due to the high cooling rates during SLM, it is expected to be a promising manufacturing method to refine the primary Si in high Si containing $\mathrm{Al}$ alloys. The feasibility to produce dense parts with optimized process parameters has been shown for a variety of materials, such as Ti based [8, 9], Ni based [10, 11] and $\mathrm{Fe}$ based [12] alloys. However, $\mathrm{Al}$ and its alloys show high reflectivity and thermal conductivity making SLM more challenging [13]. Additionally, Al powders exhibit reduced flowability which inhibits spreading of a thin powder layer. In the past, research on SLM of aluminum alloys has been focused on near-eutectic casting alloys, such as AlSi10Mg and AlSi12 [14-19], due to their good weldability and flowability. Read et al. [14] and Siddique et al. [17] investigated the influence of process parameters on part density for those alloys and were able to achieve densities $\geq 99 \%$ by optimization of process parameters. Additionally, Siddique et al. [17] analyzed the dependence of dynamic and static mechanical properties of AlSi12 on process parameters. Static strength was found superior to cast material, which was attributed to the fine microstructure obtained by SLM. Similarly, Li et al. [18] investigated the influence of post process heat treatments on the mechanical properties of SLMed AlSi10Mg. As Si particles and cells are coarsened ductility can be increased on the expense of strength. Furthermore, the influence of powder quality, fresh vs. used powder, on mechanical properties and density was investigated by Tradowsky et al. [15]. In addition, there is an increased interest in the investigation of physical properties of SLMed Aluminum alloys, such as corrosion [19].

Prealloyed powder is used in the majority of studies on SLM, while few studies are available using powder mixtures. The advantage of using powder mixtures over prealloyed powders, is the tailorability of mechanical and physical properties by adjustment of the powder fractions and the potential for creating gradient materials. Furthermore, the use of powder mixtures might facilitate the processing of alloys which were found unsuitable for manufacturing by SLM as prealloyed powders [20, 21]. Early work was focused on the fabrication of composites by adding ceramic particles as reinforcement of the metal matrix [22,23]. Densities $\geq 97 \%$ and $\geq 99.5 \%$ were achieved for Ti reinforced with $\mathrm{TiC}$ [22] and $\mathrm{TiB}$ particles (using a mixture of $\mathrm{Ti}$ and $\mathrm{TiB}_{2}$ parti- 
cles as initial powder) [23], respectively. The particle size and distribution was found to change with processing parameters with coarser particles obtained at higher input energies leading to a reduced strengthening effect [22]. Beside the benefits, inhomogeneous distribution of the constituent elements and unmolten/partially molten powder particles are major challenges in SLM of mixed powders as reported for Ti6Al4V with Mo addition [24] and aluminum alloys with Si addition [21, 25]. Furthermore, processing parameters optimized for prealloyed powder have to be adjusted when processing powder mixtures as constituents with varying melting temperatures have to be molten [25]. More recently increased research interest has been devoted to the fabricability as well as mechanical and physical properties of SLMed hypereutectic AlSi alloys using prealloyed powders [26-28] and powder mixtures [29-31], respectively. Kimura et al. [27] investigated the densification behavior, mechanical properties and thermal conductivity for a range of prealloyed hypoeutectic, eutectic and hypereutectic AlSi alloys as well as pure Al. The energy input required to achieve optimum density scattered in a range of $50 \mathrm{~J} / \mathrm{mm}^{3}$ to $60 \mathrm{~J} / \mathrm{mm}^{3}$ for alloys containing more than $6 \mathrm{wt} \% \mathrm{Si}$ and thermal conductivity was found to decrease with increasing Si content to a minimum of $105 \mathrm{~W} / \mathrm{m} \mathrm{K}$ for AlSi20. Microstructural evolution and mechanical properties have also been investigated for powder mixtures of AlSi50 [30, 31] and AlSi18 [29]. Jia et al. [28] are the only researchers reporting on the CTE of as-built as well as heat treated AlSi50 produced by SLM. However, those samples were manufactured from prealloyed powder. Therefore, in the present work the range of CTE investigations on hypereutectic AlSi alloys fabricated by SLM is extended to mixtures of AlSi alloy and $\mathrm{Si}$. For comparability an AlSi alloy containing $50 \mathrm{wt} \%$ is chosen in this investigation. Additionally, an alloy containing less $\mathrm{Si}$, AlSi25, is investigated to study the influence of Si content on processability and properties. The purpose of the presented work is twofold: first, to find a suitable processing window with respect to laser power and scan speed for manufacturing sound parts of strongly hypereutectic AlSi alloys. Second, to evaluate the tailorability of linear CTE by deliberate adjustment of powder fractions.

\section{Materials and Methods}

In this study gas atomized AISi10Mg powder with a mean particle size of $39 \mu \mathrm{m}$ served as base alloy and was blended with Si powder with mean size of $44 \mu \mathrm{m}$ to achieve desired total $\mathrm{Si}$ contents of $25 \mathrm{wt} \%$ and $50 \mathrm{wt} \%$. The two investigated compositions will thus be called AlSi25 and AlSi50 in what follows. Both powders were supplied by TLS Technik GmbH \& Co Spezialpulver KG (Bitterfeldt, Germany) and had a spherical morphology with the Al powder containing small satellite particles (Figure 1a and Figure 1b). The corresponding particle size distributions measured by laser diffraction are shown in Figure 1c. The chemical composition of the AlSi10Mg base alloy is shown in Table 1. The powders were mixed in a shaker box for $5 \mathrm{~min}$. The Hausner ratio [32], which is a measure of powder flowability, was evaluated to 1.16 for both powder mixtures indicating good flowability.

A Concept Laser M2 Cusing (Lichtenfels, Germany) equipped with a Nd:YAG fiber laser operated in continuous wave mode was used for sample manufacturing. To optimize process parameters cubic samples with an edge length of $10 \mathrm{~mm}$ were produced at varying laser power and scan speeds. Layer thickness and hatch spacing were fixed 
Table 1: Composition of AlSi10Mg powder, wt $\%$

\begin{tabular}{cccccccc}
\hline $\mathrm{Al}$ & $\mathrm{Si}$ & $\mathrm{Mg}$ & $\mathrm{Fe}$ & $\mathrm{Mn}$ & $\mathrm{Cu}$ & $\mathrm{Zn}$ & $\mathrm{Ti}$ \\
\hline Bal. & $10.3 \pm 2.5$ & $0.7 \pm 0.1$ & $<0.4$ & $<0.07$ & $<0.1$ & $<0.2$ & $<0.06$ \\
\hline
\end{tabular}

to $30 \mu \mathrm{m}$ and $120 \mu \mathrm{m}$, while laser power and scan speed were varied between $125 \mathrm{~W}$ to $400 \mathrm{~W}$ and $750 \mathrm{~mm} / \mathrm{s}$ to $2000 \mathrm{~mm} / \mathrm{s}$ respectively.

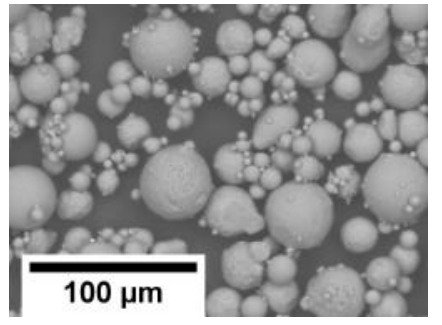

(a)

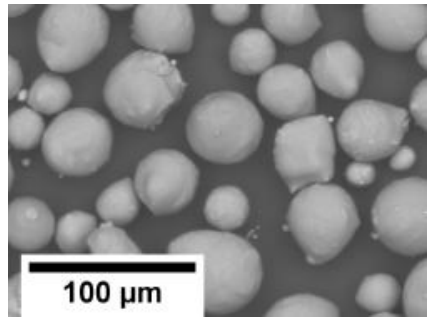

(b)

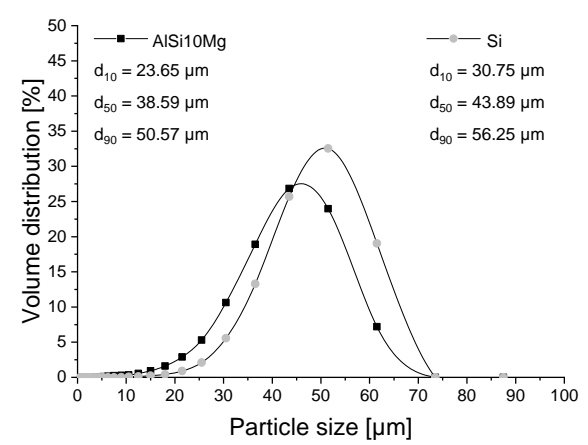

(c)

Figure 1: Characteristics of the initial powder, SEM micrographs showing morphology of a) AlSi10Mg and b) Si powder and c) according particle size distributions

Table 2 gives an overview of the investigated combinations for each Si composition. All four scan speeds were evaluated at each laser power, providing a total of 28 combinations for AlSi25 and 8 parameter sets for AlSi50. The processing was carried out under argon atmosphere with oxygen content $<0.1 \%$ to limit oxidation. All samples were fabricated using an island scanning strategy with an island size of $5 \mathrm{~mm}$, alternating scan direction and $90^{\circ}$ rotation of the laser tracks between single islands. Additionally, the island pattern was shifted by $1 \mathrm{~mm}$ in $\mathrm{x}$ - and y-direction and rotated by $45^{\circ}$ after each layer to avoid built up of defects between island borders. The scanning strategy is illustrated in Figure 2. To characterize the influence of process parameters on relative density the energy density $E_{D}$ of each parameter set was calculated as

$$
E_{D}=\frac{P}{v \cdot t \cdot h}
$$




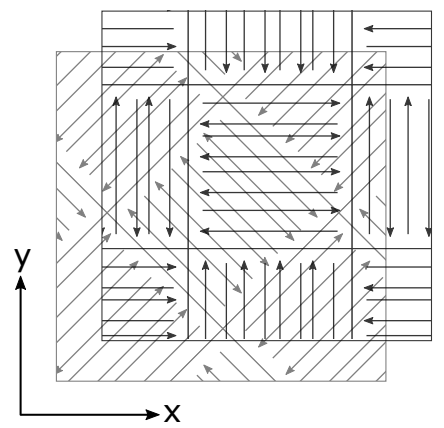

Figure 2: Schematic drawing of island scanning strategy and shift of the scanning pattern for consecutive layers

where $P$ is laser power, $v$ is scan speed, $t$ is layer thickness and $h$ is hatch spacing.

Sample cubes were cut in the y-z plane, mounted in cold resin and polished to $0.04 \mu \mathrm{m}$ finish for porosity and microstructural analysis. Porosity content was calculated by analyzing mosaic images from the center of the samples recorded at a magnification of 100 and stitched to a field of 9 x 10 images using a Zeiss Axioskop optical microscope and ImageJ software [33] (see stitched images in Figure 3 and Figure 6). The total area analyzed was about $33 \mathrm{~mm}^{2}$. For microstructural observation samples were etched in sodium hydroxide and analyzed by a Zeiss Leo Gemini 1530 SEM operated at $15 \mathrm{kV}$.

For CTE measurements cylindrical samples were produced with scanning speed of $1500 \mathrm{~mm} / \mathrm{s}$ and laser power of $350 \mathrm{~W}$ for AlSi2 25 and $750 \mathrm{~mm} / \mathrm{s}$ and $325 \mathrm{~W}$ for AlSi50. Those parameters were found suitable to produce samples with relative densities $>99 \%$ for each composition. A higher energy input is needed for the alloy containing a higher fraction of $\mathrm{Si}$ as will be discussed in subsection 3.1. The cylinders were turned to final diameter of $5 \mathrm{~mm}$ and a length of $10 \mathrm{~mm}$. A Bähr-Thermoanalyse dilatometer $805 \mathrm{~A} / \mathrm{D}$ with induction heating and argon atmosphere was used to measure thermal expansion in a temperature range from $50{ }^{\circ} \mathrm{C}$ to $400{ }^{\circ} \mathrm{C}$. The heating rate was $1{ }^{\circ} \mathrm{C} / \mathrm{s}$. Three full temperature cycles were performed on each sample with two samples for each $\mathrm{Si}$ content. During the first cycle residual stresses from SLM processing were released and only the second and third cycle were used to calculate the average CTE values.

Table 2: Combinations of scan speed and laser power, $\mathrm{X}$ indicates parameter sets investigated for AlSi25 and O for AlSi50

\begin{tabular}{|c|c|c|c|c|c|c|c|c|}
\hline & \multicolumn{7}{|c|}{ Laser power [W] } \\
\hline & & 125 & 175 & 225 & 275 & 325 & 375 & 400 \\
\hline & 750 & $\mathrm{X}$ & $\mathrm{X}$ & $\mathrm{X}$ & $\mathrm{X}$ & $\mathrm{XO}$ & $\mathrm{X}$ & $\mathrm{XO}$ \\
\hline E & 1000 & $X$ & $X$ & $X$ & $X$ & XO & $X$ & XO \\
\hline$\frac{2}{2}$ & 1500 & $X$ & $X$ & $X$ & $X$ & $\mathrm{XO}$ & $X$ & $\mathrm{XO}$ \\
\hline$\ddot{n}$ & 2000 & $\mathrm{X}$ & $\mathrm{X}$ & $\mathrm{X}$ & $\mathrm{X}$ & $\mathrm{XO}$ & $\mathrm{X}$ & $\mathrm{XO}$ \\
\hline
\end{tabular}




\section{Results and discussion}

\subsection{Influence of process parameters on density}

In order to investigate the influence of laser power and scan speed on porosity formation at fixed layer thickness and hatch spacing, those two parameters were varied according to Table 2. The reproducability of results was checked by determining the porosity of six additional samples for AlSi25 produced at one constant set of parameters $(350 \mathrm{~W}$ and $1500 \mathrm{~mm} / \mathrm{s})$. The average relative density evaluated for those samples was $99.90 \pm 0.05 \%$. Although the variation in density was only checked for one set of parameters it is assumed that scatter will be low for the other parameter sets as well. In general, opposite trends can be observed for low and high laser power regimes in both investigated powder mixtures. For the AlSi25 alloy a similar dependence of scan speed and laser power is observed for laser power up to $225 \mathrm{~W}$ and those parameter sets are therefore considered as belonging to the low power regime. Dense parts could not be produced at a constant laser power of $125 \mathrm{~W}$ within the range of investigated scan speeds. For the remaining two laser powers associated with the low power regime, $175 \mathrm{~W}$ and $225 \mathrm{~W}$, the evolution of density with scan speed is shown in Figure 3a. As expected the relative density decreases with increasing scan speed and thus decreasing energy input. Stitched SEM images illustrate the increase in irregularly shaped pores with increasing scan speed and decreasing density. The pores contain unmelted powder particles and are therefore related to insufficient melting of neighboring and underlying scan tracks. Sufficient energy input to produce dense parts is only achieved at scan speeds below $1000 \mathrm{~mm} / \mathrm{s}$ at laser power higher than $175 \mathrm{~W}$. With increasing laser power to $225 \mathrm{~W}$ the range of suitable scan speeds is extended to $1500 \mathrm{~mm} / \mathrm{s}$, thus broadening the process window (Figure 4).

In the case of applied laser power $\geq 275 \mathrm{~W}$ an opposite trend was observed as shown in Figure 3b. In contrast to the behavior at laser power $\leq 225 \mathrm{~W}$, density decreases with decreasing scan speed. At a scan speed of $750 \mathrm{~mm} / \mathrm{s}$ all applied laser powers show relative densities below $99 \%$. However, compared to the lack of fusion porosity shown in the insets of Figure 3a pores obtain a rather spherical shape and are located at the tip of deep and narrow weld pools as shown in Figure 5. Due to the pore shape and location it can be inferred that the decrease in density is due to melt pool instability at very high input energies. A decrease of scan speed or increase of laser power enhances laser-material interaction and causes deep and narrow weld pools which easily become unstable leading to the entrapment of processing gas causing so called keyhole pores [34]. The alignment of the pores visible in Figure 5 might thus be caused by overheated regions at the end of the scan tracks as the laser slows down to turn for the neighboring track (skywriting was not enabled during sample processing).

A similar change in relation of scan speed, laser power and relative density in dependence on laser power range is observed for AlSi50. At a laser power of $325 \mathrm{~W}$ density decreases with increasing scan speed and at a laser power of $400 \mathrm{~W}$ density increases with increasing scan speed (Figure 6). The transition laser power separating those two behaviors is increased compared to AlSi25 for which the transition occurred between $250 \mathrm{~W}$ and $275 \mathrm{~W}$. A possible explanation could be that the increase in $\mathrm{Si}$ 


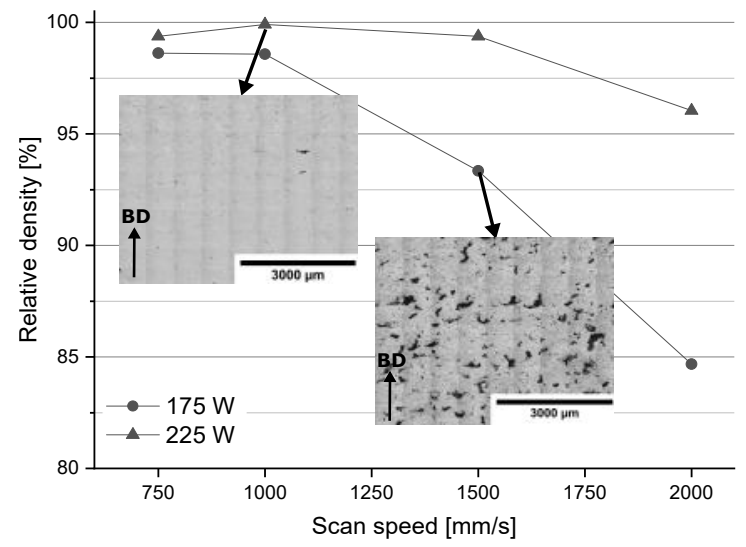

(a)

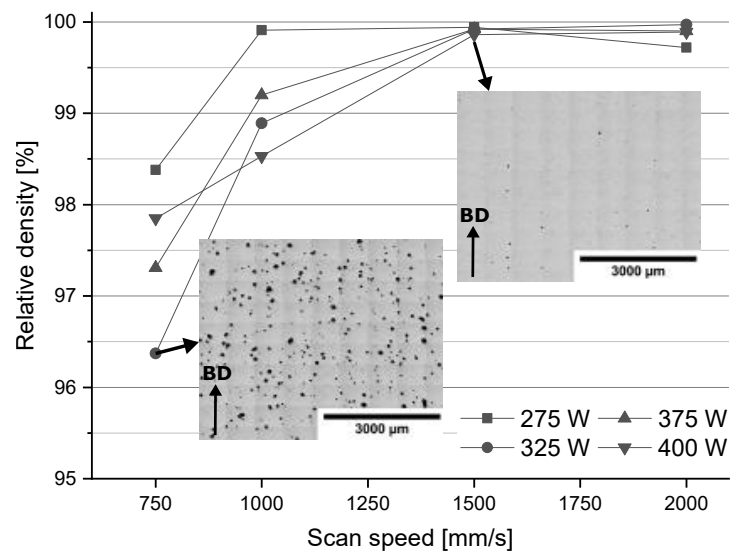

(b)

Figure 3: Relative density of AlSi25 samples over scan speed for laser power a) $\leq 225 \mathrm{~W}$ and b) $\geq 275 \mathrm{~W}$, insets show stitched micrographs of selected samples, BD is building direction

content increases the energy required to fully melt the powder, due to the increase in

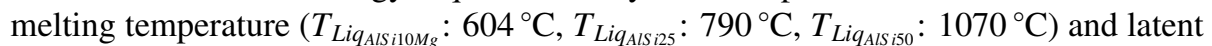
heat of fusion with $\mathrm{Si}$ addition. The liquidus temperatures are stated for the alloys as the powder should be completely molten during SLM. Additionally, as mixed powders are used instead of prealloyed powder, each component has to be molten to enable chemical mixing in the liquid state. In this case, the Si powder is the one with the higher melting point $\left(T_{m_{S i}}: 1430^{\circ} \mathrm{C}\right)$ making it more difficult to create a sufficient melt pool as Si fraction increases. A similar observation was made by Kang et al. [25] reporting that a higher energy input is needed for processing AlSi12 powder mixture compared to a prealloyed powder to reach the same density. The increased silicon content in AlSi50 compared to AlSi25 therefore extends the region exhibiting an increase in density with decreasing scan speed/increasing energy input to higher laser power. However, as mixed powders are used in the present investigation the high laser power 


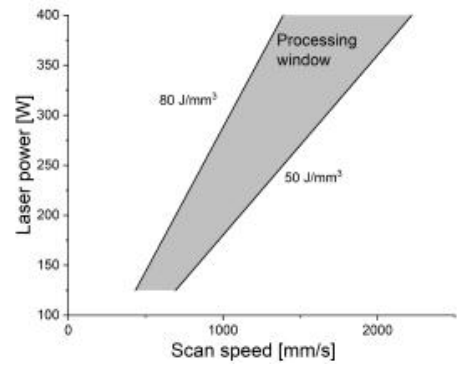

Figure 4: Extension of processing window with increasing laser power for AlSi25

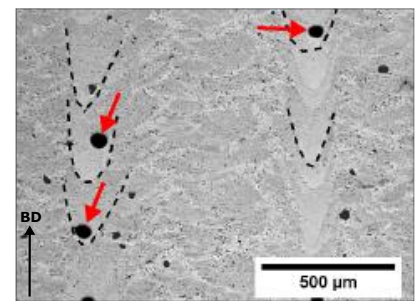

Figure 5: Micrograph of AlSi25 sample produced at $400 \mathrm{~W}$ and $2000 \mathrm{~mm} / \mathrm{s}$, some melt pools are marked by dotted lines and keyhole porosity is indicated by red arrows, BD is building direction

necessary to melt the Si powder particles could cause melt pool instability and evaporation due to overheating of the Si poor aluminum matrix melt pool. The melt pool instability would then cause the formation of keyholes and therefore reduce the part density. Evaporation of Al during the fabrication of a mixed AlSi alloy was observed by Kang et al. [29] starting at an energy input of $151 \mathrm{~J} / \mathrm{mm}^{3}$ which is close to the highest energy density of $148 \mathrm{~J} / \mathrm{mm}^{3}$ used in the present investigation.

To compare the influence of energy density on the densification behavior of both alloys, the relative density is plotted in Figure 7 as a function of energy density calculated by Equation 1. Relative density values are in a comparable range for similar energy densities for both Si compositions. For energy densities in the range of $50 \mathrm{~J} / \mathrm{mm}^{3}$ to $80 \mathrm{~J} / \mathrm{mm}^{3}$ and $63 \mathrm{~J} / \mathrm{mm}^{3}$ to $95 \mathrm{~J} / \mathrm{mm}^{3}$ relative densities above $99 \%$ can be achieved for AlSi25 and AlSi50 respectively. However, as the lowest energy density investigated for the AlSi50 alloy is higher than $50 \mathrm{~J} / \mathrm{mm}^{3}$ and sample number was small, a final conclusion cannot be drawn on the optimal energy density window in comparison to the lower Si alloy. At higher energy densities the relative density of both alloys is decreased by keyhole porosity as indicated by metallographic examination. The input energy for complete densification lies in a comparable range as for other AlSi alloys [27] and is lower than that found for higher melting point alloys such as CP-Ti [35] and Ti6Al4V [32] $\left(120 \mathrm{~J} / \mathrm{mm}^{3}\right)$. Although energy density is a useful parameter for general process qualification, it should be taken with care as Attar et al. [35] and Bertoli et al. [35] have shown that different process parameters influence melt pool shape and stabil- 


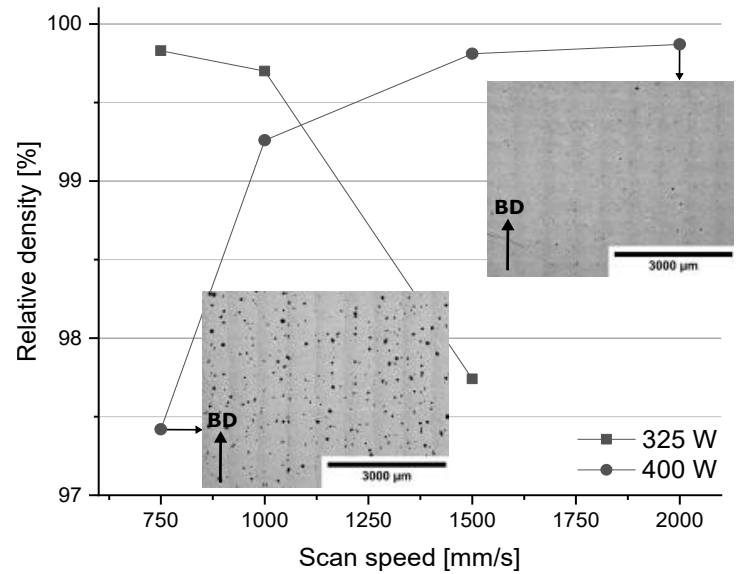

Figure 6: Relative density of AlSi50 samples over scan speed for laser power of $325 \mathrm{~W}$ and $400 \mathrm{~W}$, BD is building direction

ity in different ways. This could explain the scatter observed in the region of complete densification in Figure 7 as not all parameter combinations reach the expected density.

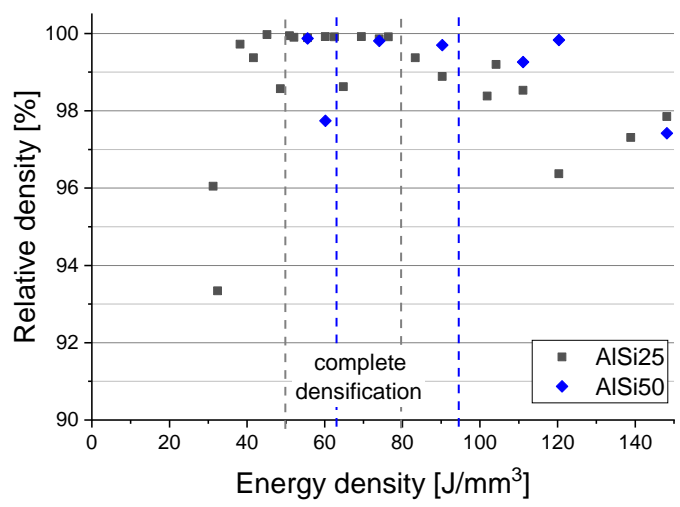

Figure 7: Relative density over input energy density

\subsection{Influence of process parameters on crack formation}

Whole cross sections of the cut sample cubes were investigated by optical microscopy for the occurrence of cracks. Beside some minor cracking directly at the interface between sample and base plate, none of the fabricated AlSi25 samples showed crack formation. In contrast, cracks were observed in all AlSi50 samples beside the sample produced at $400 \mathrm{~W}$ and $750 \mathrm{~mm} / \mathrm{s}$ as shown in Figure 8. Crack formation was reduced with increasing laser power and/or decreasing scan speed which correlates with 
increasing input energy density. However, an increase in energy input led to the formation of excessive keyhole porosity (Figure $8 \mathrm{~b}$ and $8 \mathrm{c}$ ) and, thus, a balance between crack formation and porosity has to be found.

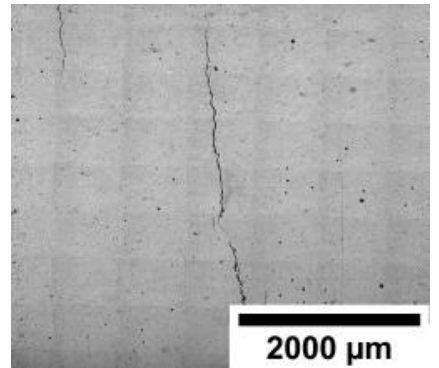

(a)

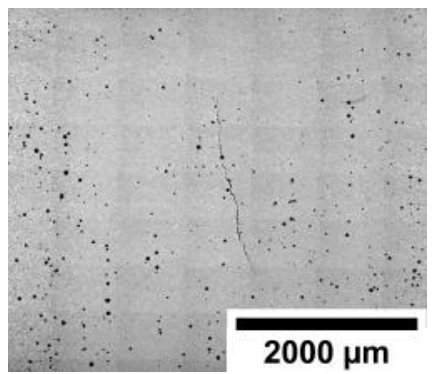

(b)

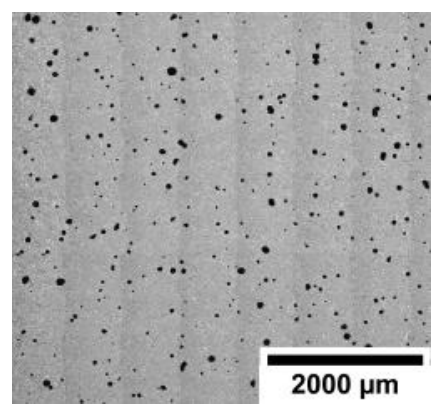

(c)

Figure 8: Cross section micrographs of AlSi50 samples processed at an input energies of a) $74 \mathrm{~J} / \mathrm{mm}^{3}$, b) $111 \mathrm{~J} / \mathrm{mm}^{3}$ and c) $148 \mathrm{~J} / \mathrm{mm}^{3}$, BD is building direction

Crack formation is attributed to high thermal stresses during SLM processing, due to steep thermal gradients (about $10^{6} \mathrm{~K} / \mathrm{m}$ [16]), fast cooling rates (about $10^{6} \mathrm{~K} / \mathrm{s}$ [36]) and CTE mismatch between baseplate and sample material. The latter could explain why cracks are formed within the AlSi50 samples, while no cracks were found in the AlSi25 samples. As will be discussed in subsection 3.4 the CTE value decreased with increasing Si content, thus, leading to a larger CTE difference for the higher Si containing alloy compared to the $\mathrm{Al}$ base plate. A possible explanation for the decreased crack susceptibility with higher laser power and slower scan speeds might be the decrease in thermal gradient and cooling rate due to heat accumulation within the parts during processing [37]. Simulations of the temperature profile and residual stresses of SLMed Ti6Al4V by Parry et al. [37] indicate that heat can be accumulated during processing and thermal stresses thereby reduced. In contrast, Li and Gu [38] observed an increase in cooling rate and thermal gradient with increasing laser power in their simulations on the thermal behavior of AlSi10Mg, which would imply that thermal stresses should be enhanced with increasing laser energy input. Furthermore, the samples built in the present investigation showed keyhole porosity at high input energies, 
which might contribute to the release of residual stresses. As the thermal history of SLMed parts is complex and depends on many parameters, a comprehensive explanation for the reduced cracking cannot be stated yet and further investigation is needed.

Crack formation has not been reported by other research groups investigating SLMed AlSi50 alloy fabricated from prealloyed [28] as well as elemental powder mixtures [30, 31]. In case of the works of Kang et al. [30, 31] the difference might be explained by the use of a preheated base plate as well as high energy densities $\left(231 \mathrm{~J} / \mathrm{mm}^{3}\right.$ to $320 \mathrm{~J} / \mathrm{mm}^{3}$ ) which both will reduce thermal stresses as discussed above. However, the energy input reported by Jia et al. [28] was low (about $40 \mathrm{~J} / \mathrm{mm}^{3}$ ) compared to the energy input range used in the present investigation. The lack of cracks can thus not be attributed to the difference in input energy and might be a result of the difference in initial material, which was prealloyed powder in the case of Jia et al. [28]. Additionally, as thermal history of SLMed parts is strongly dependent on part geometry as well as scan strategy, the difference in crack formation might also be attributed to different scan patterns as well as sample sizes used by the different research groups.

\subsection{Microstructure}

\subsubsection{AlSi25}

Round Si particles within the size range of $35 \mu \mathrm{m}$ to $55 \mu \mathrm{m}$ were visible in the cross sections of polished and etched AlSi25 samples (Figure 9a). With increasing laser power or decreasing scan speed the number of observed particles decreased. This observation as well as their size range and morphology indicate that those are pure $\mathrm{Si}$ powder particles which were not molten during SLM processing. Since the investigated powders are not prealloyed, but simple mechanical mixtures, the $\mathrm{Al}$ alloy and $\mathrm{Si}$ powder particles will interact differently with the laser. Due to the high melting point of $\mathrm{Si}$ compared to the Al base alloy, the melting of Si particles will require significantly more energy. Additionally, the melting of those particles could have been impeded due to their size or location within the powder bed. However, some of the particles seemed to be broken and dissolved within the molten Al base alloy (Figure 9b). The dissolved Si than re-solidifies as primary Si particles (Figure 10a). Investigating the fabricability of AlSi powder mixtures Kang et al. [25, 29] observed partially molten Si powder particles. Similarly, Roberts et al. [20] assumed the Si powder particles in their AlSi mixture not to be molten but encapsulated by the surrounding Al melt pool. Therefore, a post heat treatment was applied to facilitate Si dissolution. In both works Si particle size was considerably smaller (mean size of $4 \mu \mathrm{m}$ to $6 \mu \mathrm{m}$ ) compared to the present investigation (mean size of $44 \mu \mathrm{m}$ ), while input energies were in a comparable range of $71 \mathrm{~J} / \mathrm{mm}^{3}$ to $267 \mathrm{~J} / \mathrm{mm}^{3}$. Thus, it is likely that the larger Si powder particles in the present investigation were not completely molten and it is recommended to use smaller sized particles for future investigations. Although melting of Si particles can be facilitated by high energy input, energies above the keyholing threshold will decrease achievable part density. As for cracking of AlSi50 a trade off between part density and complete dissolution of Si within the base alloy melt has to be found.

Beside unmolten Si particles the typical fish scale pattern formed due to the layer by layer and track by track fabrication process is visible in Figure 9. Each scan track can be divided into a melt pool core zone and a melt pool border, due to the different 


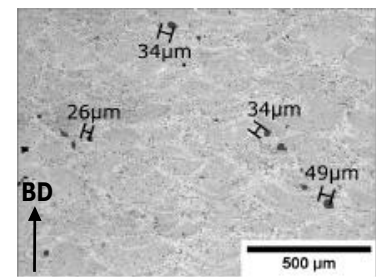

(a)

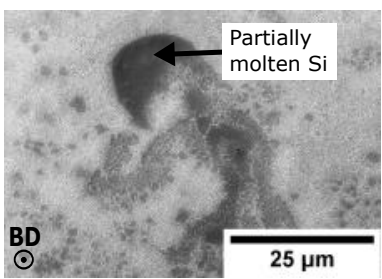

(b)

Figure 9: Unmolten/Partially molten Si particles in AlSi25 samples, a) $76 \mathrm{~J} / \mathrm{mm}^{3}$ and b) higher magnification image $\left(52 \mathrm{~J} / \mathrm{mm}^{3}\right)$

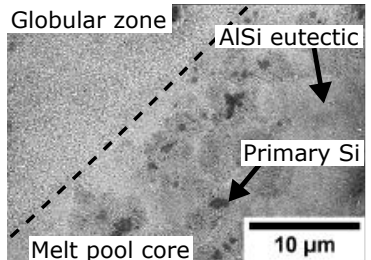

(a)

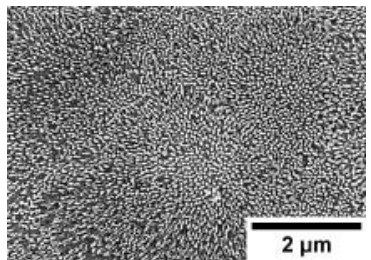

(c)

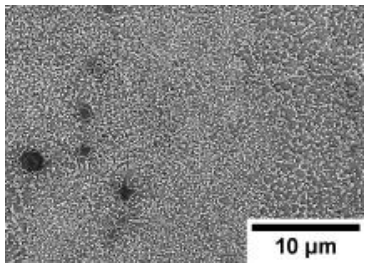

(b)

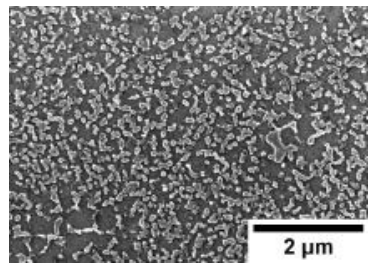

(d)

Figure 10: SEM images of the microstructure of AlSi25 in asbuilt condition, (a) melt pool core and border with network and globular zone, (b) after CTE measurement and higher magnification images of eutectic (c) and globular zone (d) in as built condition, building direction in plane

thermal histories [16]. The microstructure of the different regions is shown in Figure 10. The melt pool core was observed to consist of primary Si particles surrounded by $\alpha$-aluminum, which is in turn surrounded by Al-Si-eutectic (Figure 10a). Due to the high cooling rates achieved by SLM, the eutectic shows a fine fibrous morphology (Figure 10c). The melt pool border consists of small $(\leq 1 \mu \mathrm{m})$ globular shaped Si particles and is therefore called the globular zone (Figure 10d). This zone is possibly created since the melt pool border experiences reheating during the scanning of neighboring tracks, thus, causing coarsening and spheroidization of the eutectic Si. During CTE measurement the fine eutectic observed in asbuilt condition coarsened to a comparable size as for the globular zone and the separation between core and boarder zone was less visible on micrographs after the measurement (Figure 10b). 


\subsubsection{AlSi50}

Similar to AlSi25 the primary and eutectic Si is considerable refined due to SLM processing (Figure 11a). The primary Si particles in the coarse and fine region of the SLMed AlSi50 obtain a mean size of about $7 \pm 3 \mu \mathrm{m}$ and $4 \pm 1 \mu \mathrm{m}$ respectively compared to a primary Si size greater $200 \mu \mathrm{m}$ [28] in the cast state. Additionally, the primary particles are more rounded in the SLMed samples compared to cast AlSi50. The fine Al-Si eutectic is visible between the primary Si particles in Figure 11b. The

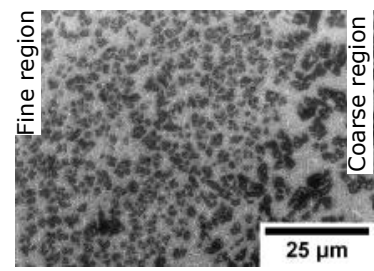

(a)

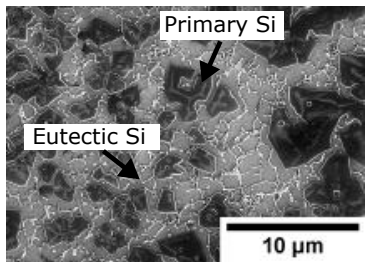

(b)

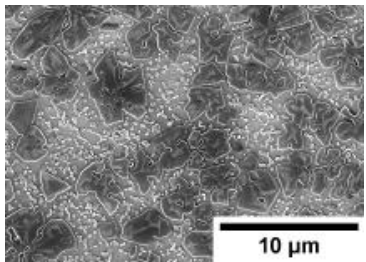

(c)

Figure 11: Microstructure of asbuilt $\operatorname{AlSi50}\left(120 \mathrm{~J} / \mathrm{mm}^{3}\right)$, a) fine and coarse melt pool regions, b) higher magnification image of fine primary $\mathrm{Si}$ and $\mathrm{Al}-\mathrm{Si}$ eutectic and (c) microstructure after CTE measurement, micrographs with building direction in plane

microstructure after the CTE measurement is shown in Figure 11c. Similar to the AlSi25 alloy the eutectic Si spheroidized while no change in primary Si size is visible.

\subsection{Influence of silicon content on thermal expansion}

The average CTE values measured in the range of $50{ }^{\circ} \mathrm{C}$ to $400{ }^{\circ} \mathrm{C}$ are displayed in Figure 12a. The decrease of CTE with Si addition is obvious within the whole temperature range investigated. For comparison CTE values for pure $\mathrm{Al}$ and $\mathrm{Si}$ taken from [28] are indicated as solid lines. Compared to pure aluminum the temperature dependence of the AlSi alloys is reduced due to the lower temperature dependence of CTE for pure Si.

As AlSi alloys can be treated as metal matrix composites, the experimental results of the two alloys are compared to calculated CTE using the rule of mixtures (ROM) and the Turner model. The ROM assumes a serial deformation process of both constituents, the matrix and the filler, and does not take into account any restrictions from the reinforcing phase on the expansivity of the matrix. Therefore, the ROM depicts the upper bound of the composite CTE. According to the ROM the CTE is calculated as

$$
\alpha_{R O M}=\alpha_{S i} V_{S i}+\alpha_{A l} V_{A l}
$$


Table 3: Elastic moduli E, Poisson's ratios $v$ and CTE $\alpha$ of pure Al and Si used for modelling [39]

\begin{tabular}{lcccccc}
\hline \multirow{2}{*}{ Temperature $\left[{ }^{\circ} \mathrm{C}\right]$} & \multicolumn{3}{c}{$\mathrm{Al}$} & \multicolumn{3}{c}{$\mathrm{Si}$} \\
& $\mathrm{E}[\mathrm{GPa}]$ & $v[-]$ & $\alpha\left[10^{-6} \mathrm{~K}^{-1}\right]$ & $\mathrm{E}[\mathrm{GPa}]$ & $v[-]$ & $\alpha\left[10^{-6} \mathrm{~K}^{-1}\right]$ \\
\hline 50 & 69.2 & 0.33 & 22.6 & 163 & 0.22 & 2.5 \\
100 & 67.6 & 0.33 & 24.2 & 162 & 0.22 & 3.0 \\
200 & 64.0 & 0.33 & 25.7 & 161 & 0.22 & 3.4 \\
300 & 59.8 & 0.34 & 27.7 & 160 & 0.22 & 3.6 \\
400 & 54.9 & 0.36 & 30.4 & 156 & 0.22 & 3.8 \\
\hline
\end{tabular}

with CTE values $\alpha$ and volume fractions $V$. In contrast, the Turner model (Equation 3) assumes a parallel deformation process and, thus, depicts the lower limit of CTE taking into account the constraint on matrix expansion by the reinforcing phase. The Turner model CTE is calculated as

$$
\alpha_{\text {Turner }}=\frac{\alpha_{S i} V_{S i} K_{S i}+\alpha_{A l} V_{A l} K_{A l}}{V_{S i} K_{S i}+V_{A l} K_{A l}}
$$

where $K$ is the bulk modulus. The temperature dependent CTE $\alpha$, Elastic moduli $E$ and Poisson's ratios $v$ of pure $\mathrm{Al}$ and $\mathrm{Si}$ used to calculate the CTE values are stated in Table 3. The bulk moduli are calculated using the relation of Elastic modulus and Poisson's ratio with bulk modulus (Equation 4).

$$
K_{x}=\frac{E_{x}}{3\left(1-2 v_{x}\right)}
$$

The volume fractions of $\mathrm{Si}$ and $\mathrm{Al}$ may be estimated using the following three techniques:(1) Rietveld refinement of XRD spectra, which is the most accurate, but also the most demanding method, (2) quantitative image analysis using the area fraction as equivalent, however, small precipitates might be missed in image analysis and (3) using the nominal compositions of the investigated alloys and calculating the volume fractions using the elemental densities. The third method is simple and quick, thus, it is used to calculate the volume fractions in this investigation. Error can be introduced by taking the densities of the pure elements instead of the solid solutions. However, the solubility of $\mathrm{Si}$ in $\mathrm{Al}$ at room temperature is negligible $(0.05 \mathrm{wt} \%)$. Although solubility of $\mathrm{Si}$ in $\mathrm{Al}$ can be increased due to the high cooling rates of SLM, it is expected that the supersaturated $\mathrm{Si}$ is precipitated on heating the asbuilt samples, which is supported by the irreversible length change observed after the first cycling for the CTE measurement. Since only the second and third cycle are used for CTE calculation and no additional length change was observed, the error from above assumption is expected to be negligibly small.

The calculated CTEs are shown in comparison with experimental results in Figure 12a. As expected the experimental CTE fall below the ones calculated by the ROM for AlSi25 and AlSi50, respectively. Although the thermal expansion behavior of the AlSi50 samples are lower than predicted by ROM it is closer to the calculated CTE compared to AlSi25. The opposite can be stated for the Turner model. While 
the AlSi25 samples are in accordance with the Turner model prediction, the CTE for AlSi50 calculated by this model are lower than the experimentally observed ones. The different behavior between the AlSi25 and AlSi50 alloy might be explained by the different microstructures. As the material at the interface of the reinforcing particles and the matrix is constrained in expansion by the lower expansivity of the reinforcing phase, the CTE depends on the particle size of the reinforcement and the volume to surface ratio [40]. The AlSi25 alloy obtains a finer microstructure, subsection 3.3, which could put higher constraints on the aluminum matrix as the interface area is increased compared to the coarser AlSi50 microstructure. Thus, the CTE of the AlSi25 alloy falls closer to the Turner model taking into account the additional constraints from the interface regions. Figure 12 additionally contains literature data for prealloyed AlSi50 manufactured by SLM [28] as well as spray formed AlSi27 [41] as a comparison for the AlSi50 and AlSi25 alloy investigated within this work. For AlSi27 two points are given at each temperature depicting the lower and upper bounds observed by Zhu et al. [41] with variation of heat treatment. The influence of heat treatment on CTE was explained by three effects: (1) The release of residual stresses built up during the spray forming, (2) The precipitation of $\mathrm{Si}$ from the saturated $\mathrm{Al}$ matrix and coarsening of primary $\mathrm{Si}$ particles and (3) the change in bulk modulus. Build up of stresses is also an issue in SLM, subsection 3.2, however, an irreversible length change appeared during the first cycle of the CTE measurement and the second and third cycle were stable. Therefore, it is assumed that residual stresses would have been released during the first heat up. Additionally, the irreversible length change during the first cycle could also result from the change in microstructure as observed in subsection 3.3. Although, coarsening of the primary Si was not observed, the spheroidization of the eutectic Si and possible precipitation of $\mathrm{Si}$ from the supersaturated $\mathrm{Al}$ solid solution could lead to a change in dimension [28]. Since the CTE was stable during the second and third heatup and cool down cycles it is not expected that microstructural changes significantly influencing the CTE occurred during the following cycles. It can be seen that the AlSi25 alloy of the present investigation lies close to the lower bound of the AlSi27 alloy, which was heat treated at the lowest temperature and, thus, showed the smallest primary Si size. Regarding AlSi50, the alloy produced from mixed powders in the present investigation shows higher thermal expansion compared to the prealloyed AlSi50 alloy investigated by Jia et al. [28]. The difference in CTE in the range of $200{ }^{\circ} \mathrm{C}$ to $300{ }^{\circ} \mathrm{C}$ between the as-built and heat treated samples is explained by the precipitation of Si from the saturated $\mathrm{Al}$ matrix, which will increase the thermal expansion of the $\mathrm{Al}$ matrix. In contrast, the CTE of the heat treated AlSi50 alloy monotonically increases without a jump in CTE. As CTE is sensitive to microstructural changes, illustrated by the data for the AlSi27 alloy, the lower CTE of the AlSi50 alloy investigated by Jia et al. [28] might be attributed to the difference in microstructure. The mean primary Si size reported by Jia et al. [28] for the coarse border regions is $5.5 \mu \mathrm{m}$, in contrast to $7 \pm 3 \mu \mathrm{m}$ for our AlSi50 alloy. The finer Si particles reduce the expansivity of the aluminum matrix by increasing the interface area. Thus, the CTE of the finer AlSi50 alloy of Jia et al [28] is reduced compared to our AlSi50 alloy analyzed in the present investigation. This assumption fits the observation that our AlSi50 alloy falls close to the ROM, which is attributed to a lesser constrained matrix, while the literature AISi50 alloy is close to the Turner model. The smaller size of Si particles might be related to the lower input 
energy density of $40 \mathrm{~J} / \mathrm{mm}^{3}$ for the prealloyed AlSi50 powder compared to $120 \mathrm{~J} / \mathrm{mm}^{3}$ used in the present investigation of the mixed powder. As stated in subsection 3.3 the $\mathrm{Si}$ powder particles used in the present investigation were larger than the AlSi10Mg base alloy powder and thus high input energies had to be applied to melt/partially melt the $\mathrm{Si}$ particles. Additionally, Kang et al. [30,31] reported that Si size, shape and distribution of primary $\mathrm{Si}$ in AlSi50 critically depend on the applied processing parameters with lower laser power leading to homogeneous distribution of small globular primary Si. Therefore, improvement of CTE might be achieved by further refinement of primary Si particles using smaller Si powder and adjusting input energy.

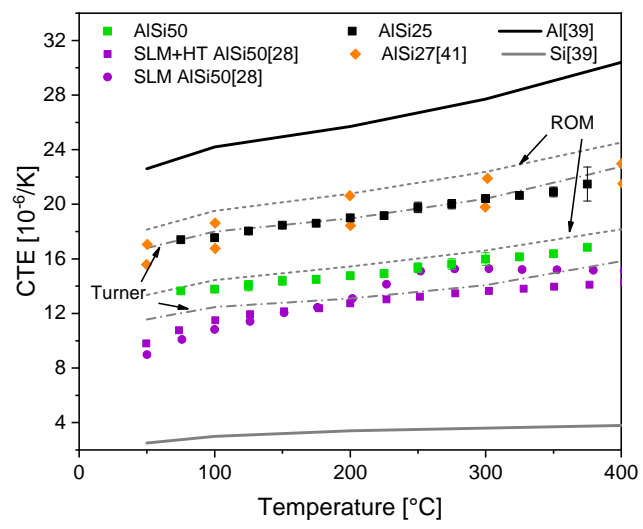

(a)

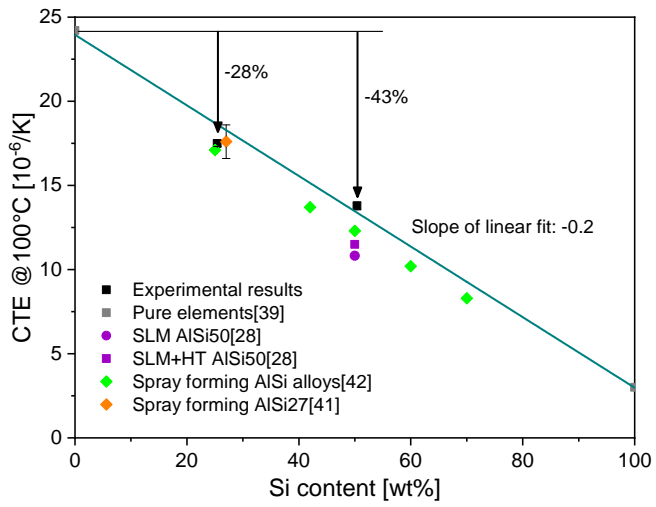

(b)

Figure 12: a) Temperature dependence of CTE for AlSi25 and AlSi50 in comparison to pure $\mathrm{Al}$ [39] and $\mathrm{Si}$ [39], SLMed AlSi50 [28] and spray formed AlSi27 [41] and b) influence of Si content on CTE reduction at $100{ }^{\circ} \mathrm{C}$ including literature data $[28,39,41,42]$

To quantify the effect of Si on the CTE of Al the CTE values for the investigated 
AlSi25 and AlSi50 alloys obtained at $100^{\circ} \mathrm{C}$ and literature data are plotted in Figure 12b. A reduction of about $0.2 \cdot 10^{-6} 1 / \mathrm{K}$ per wt $\% \mathrm{Si}$ could be achieved leading to a total reduction of $28 \%$ and $43 \%$, compared to the CTE of pure Al for AlSi25 and AlSi550 respectively. Literature data for AlSi25 and AlSi27 match the experimental CTE values, while at higher Si contents the literature data is slightly lower. As stated above, the difference in CTE between the AlSi50 alloy prepared from mixed powders in the present investigation and AlSi SLMed from prealloyed powder by Jia et al. [28] is expected to result from the different primary Si particle size. Furthermore, it is stated by Sandvik [42] that their AlSi alloys form a continuous Si network for Si contents higher than $40 \%$. The continuity of the Si phase will exert an additional constraint on the Al matrix and thus further reduce the CTE of the respective alloy. The results of the CTE measurements show that Al alloys with Si addition fabricated by combining SLM and in-situ alloying show promise for electronic packaging and thermal management applications and that CTE is largely tailorable with adjustment of Si content in the powder mixtures.

\section{Conclusions}

From the present investigation on the fabricability of in-situ AlSi10Mg+Si by SLM and tailorability of CTE with Si addition to total Si contents of $25 \mathrm{wt} \%$ and $50 \mathrm{wt} \% \mathrm{Si}$ the following main conclusions can be drawn:

- For both powder mixtures high relative densities $(\geq 99 \%)$ are achievable with adjustment of laser power and scan speed, however, the range of optimal parameter combinations is dependent on Si content.

- Depending on laser power relative densities either show a decreasing or increasing trend with scan speed: At low laser power a decrease in density is observed with increasing scan speed, due to the low heat input being insufficient to create the required melt pool size to connect surrounding scan tracks leading to lack of fusion defects. However, at high laser power density decreases with decreasing scan speed. The occurring porosity is attributed to keyhole formation.

- Cracks were observed to occur during SLM processing at low laser power and high scan speeds. However, crack formation was found to decrease by application of higher laser power and lower scan speeds. Processing with a preheated base plate is recommended to reduce thermal stresses and prevent crack formation.

- Considerable refinement of the microstructure and the primary Si particles has been achieved compared to cast material. However, not all of the Si powder particles were completely molten during processing and further research has to be done to adjust process parameters to obtain complete melting of both powder components. It is recommended to reduce the Si powder particle size in relation to the Al alloy base powder to facilitate melting of the Si particles. 
- The tailorability of CTE with adjustment of Si content has been shown. The CTE is reduced by $0.2 \cdot 10^{-6} 1 / \mathrm{K}$ per wt $\% \mathrm{Si}$, which gives a total CTE reduction of $43 \%$ for AlSi50.

\section{Acknowledgments}

TH would like to thank the School of Metallurgy and Materials, University of Birmingham, as well as the Institute for Applied Materials, Karlsruher Institute of Technology, for the possibility to do this cooperative research work. MMA, NJEA, \& LNC acknowledge the support from the Seventh European Frame Programme FP7 grant AMAZE "Additive Manufacturing Aiming towards Zero Waste and Efficient Production of High-Tech Metal Products" FP7 Grant No. NMPSE-2012-0313781 and the support of Thales-Alenia as a part of AMAZE.

Author Contributions: Theresa Hanemann performed the experiments and wrote the paper by the supervision of Moataz Attallah and Martin Heilmaier. Luke N. Carter manufactured the samples. Data has been analyzed together by Nick Adkins, Luke Carter and Theresa Hanemann. Dilatometry was performed by Moritz Habschied. All

authors contributed to the overall discussion of the manuscript and approved the final version.

Declaration of interest: None

\section{References}

[1] C. Cui, A. Schulz, K. Schimanski, and H.-W. Zoch, "Spray forming of hypereutectic Al-Si alloys," Journal of Materials Processing Technology, vol. 209, pp. 5220-5228, 2009.

[2] Y. Q. Liu, S. H. Wei, J. Z. Fan, Z. L. Ma, and T. Zuo, "Mechanical Properties of a Low-thermal-expansion Aluminum/Silicon Composite Produced by Powder Metallurgy," Journal of Materials Science, vol. 30, no. 4, pp. 417-422, 2014.

[3] D. M. Jacobson and S. P. Sangha, "Future trends in materials for lightweight microwave packaging," Microelectronics international, vol. 15, no. 3, pp. 17-21, 1998.

[4] A. G. Leatham, J. S. Coombs, J. B. Forrest, A. J. W. Ogilvy, R. Ross, and L. G. Elias, "Silicon alloys for electronic packaging," Nov. 6 2001. US Patent $6,312,535$.

[5] K. Raju, S. N. Ojha, and A. P. Harsha, "Spray forming of aluminum alloys and its composites: an overview," Journal of materials science, vol. 43, no. 8, pp. 25092521, 2008.

[6] C. W. Chien, S. L. Lee, and J. C. Lin, "Processing and properties of high volume fraction aluminium/silicon composites," Materials science and technology, vol. 19, no. 9, pp. 1231-1234, 2003. 
[7] D. Gu, W. Meiners, K. Wissenbach, and R. Poprawe, "Laser additive manufacturing of metallic components: materials, processes and mechanisms," International materials reviews, vol. 57, no. 3, pp. 133-164, 2012.

[8] C. Qiu, N. J. Adkins, and M. M. Attallah, "Microstructure and tensile properties of selectively laser-melted and of HIPed laser-melted Ti-6Al-4V," Materials Science and Engineering: A, vol. 578, pp. 230-239, 2013.

[9] B. Zhang, H. Liao, and C. Coddet, "Selective laser melting commercially pure Ti under vacuum," Vacuum, vol. 95, pp. 25-29, 2013.

[10] N. Perevoshchikova, J. Rigaud, Y. Sha, M. Heilmaier, B. Finnin, E. Labelle, and $\mathrm{X}$. Wu, "Optimisation of selective laser melting parameters for the Ni-based superalloy IN-738 LC using Doehlert's design," Rapid Prototyping Journal, vol. 23, no. 5, pp. 881-892, 2017.

[11] L. N. Carter, K. Essa, and M. M. Attallah, "Optimisation of selective laser melting for a high temperature Ni-superalloy," Rapid Prototyping Journal, vol. 21, no. 4, pp. 423-432, 2015.

[12] G. Casalino, S. Campanelli, N. Contuzzi, and A. Ludovico, "Experimental investigation and statistical optimisation of the selective laser melting process of a maraging steel," Optics $\mathcal{E}$ Laser Technology, vol. 65, pp. 151-158, 2015.

[13] E. Louvis, P. Fox, and C. J. Sutcliffe, "Selective laser melting of aluminium components," Journal of Materials Processing Technology, vol. 211, pp. 275-284, 2010.

[14] N. Read, W. Wang, K. Essa, and M. M. Attallah, "Selective laser melting of AlSi10Mg alloy: Process optimisation and mechanical properties development," Materials and Design, vol. 65, pp. 417-424, 2015.

[15] U. Tradowsky, J. White, R. Ward, N. Read, W. Reimers, and M. Attallah, "Selective laser melting of AlSi10Mg: Influence of post-processing on the microstructural and tensile properties development," Materials $\mathcal{F}$ Design, vol. 105, pp. 212$222,2016$.

[16] L. Thijs, K. Kempen, J.-P. Kruth, and J. Van Humbeeck, "Fine-structured aluminium products with controllable texture by selective laser melting of prealloyed AlSi10Mg powder," Acta Materialia, vol. 61, pp. 1809-1819, 2013.

[17] S. Siddique, M. Imran, E. Wycisk, C. Emmelmann, and F. Walther, "Influence of process-induced microstructure and imperfections on mechanical properties of AlSi12 processed by selective laser melting," Journal of Materials Processing Technology, vol. 221, pp. 205-213, 2015.

[18] W. Li, S. Li, J. Liu, A. Zhang, Y. Zhou, Q. Wei, C. Yan, and Y. Shi, "Effect of heat treatment on AlSi10Mg alloy fabricated by selective laser melting: Microstructure evolution, mechanical properties and fracture mechanism," Materials Science and Engineering: A, vol. 663, pp. 116-125, 2016. 
[19] Y. Yang, Y. Chen, J. Zhang, X. Gu, P. Qin, N. Dai, X. Li, J.-P. Kruth, and L.-C. Zhang, "Improved corrosion behavior of ultrafine-grained eutectic Al-12Si alloy produced by selective laser melting," Materials $\mathcal{E}$ Design, vol. 146, pp. 239-248, 2018.

[20] C. E. Roberts, D. Bourell, T. Watt, and J. Cohen, "A novel processing approach for additive manufacturing of commercial aluminum alloys," Physics Procedia, vol. 83, pp. 909-917, 2016.

[21] M. L. Montero-Sistiaga, R. Mertens, B. Vrancken, X. Wang, B. Van Hooreweder, J.-P. Kruth, and J. Van Humbeeck, "Changing the alloy composition of Al7075 for better processability by selective laser melting," Journal of Materials Processing Technology, vol. 238, pp. 437-445, 2016.

[22] D. Gu, Y.-C. Hagedorn, W. Meiners, K. Wissenbach, and R. Poprawe, "Nanocrystalline $\mathrm{TiC}$ reinforced Ti matrix bulk-form nanocomposites by Selective Laser Melting (SLM): Densification, growth mechanism and wear behavior," Composites Science and Technology, vol. 71, no. 13, pp. 1612-1620, 2011.

[23] H. Attar, M. Bönisch, M. Calin, L.-C. Zhang, S. Scudino, and J. Eckert, "Selective laser melting of in situ titanium-titanium boride composites: processing, microstructure and mechanical properties," Acta Materialia, vol. 76, pp. 13-22, 2014.

[24] B. Vrancken, L. Thijs, J.-P. Kruth, and J. Van Humbeeck, "Microstructure and mechanical properties of a novel $\beta$ titanium metallic composite by selective laser melting," Acta Materialia, vol. 68, pp. 150-158, 2014.

[25] N. Kang, P. Coddet, L. Dembinski, H. Liao, and C. Coddet, "Microstructure and strength analysis of eutectic Al-Si alloy in-situ manufactured using selective laser melting from elemental powder mixture," Journal of Alloys and Compounds, vol. 691, pp. 316-322, 2017.

[26] P. Ma, K. G. Prashanth, S. Scudino, Y. Jia, H. Wang, C. Zou, Z. Wei, and J. Eckert, "Influence of Annealing on Mechanical Properties of Al-20Si Processed by Selective Laser Melting," Metals, vol. 4, pp. 28-36, January 2014.

[27] T. Kimura, T. Nakamoto, M. Mizuno, and H. Araki, "Effect of silicon content on densification, mechanical and thermal properties of Al-xSi binary alloys fabricated using selective laser melting," Materials Science and Engineering: A, vol. 682, pp. 593-602, 2017.

[28] Y. Jia, P. Ma, K. Prashanth, G. Wang, J. Yi, S. Scudino, F. Cao, J. Sun, and J. Eckert, "Microstructure and thermal expansion behavior of Al-50Si synthesized by selective laser melting," Journal of Alloys and Compounds, vol. 699, pp. 548$553,2017$.

[29] N. Kang, P. Coddet, H. Liao, T. Baur, and C. Coddet, "Wear behavior and microstructure of hypereutectic Al-Si alloys prepared by selective laser melting," Applied Surface Science, vol. 378, pp. 142-149, 2016. 
[30] N. Kang, P. Coddet, H. Liao, and C. Coddet, "Macrosegregation mechanism of primary silicon phase in selective laser melting hypereutectic Al-High Si alloy," Journal of Alloys and Compounds, vol. 662, pp. 259-262, 2016.

[31] N. Kang, P. Coddet, C. Chen, Y. Wang, H. Liao, and C. Coddet, "Microstructure and wear behavior of in-situ hypereutectic Al-high Si alloys produced by selective laser melting," Materials $\mathcal{E}$ Design, vol. 99, pp. 120-126, 2016.

[32] R. Grey and J. Beddow, "On the Hausner ratio and its relationship to some properties of metal powders," Powder Technology, vol. 2, no. 6, pp. 323-326, 1969.

[33] C. A. Schneider, W. S. Rasband, and K. W. Eliceiri, "NIH Image to ImageJ: 25 years of image analysis," Nature methods, vol. 9, no. 7, p. 671, 2012.

[34] K. Kempen, L. Thijs, J. Van Humbeeck, and J.-P. Kruth, "Processing AlSi10Mg by selective laser melting: parameter optimisation and material characterisation," Materials Science and Technology, vol. 31, no. 8, pp. 917-923, 2015.

[35] H. Attar, M. Calin, L. Zhang, S. Scudino, and J. Eckert, "Manufacture by selective laser melting and mechanical behavior of commercially pure titanium," Materials Science and Engineering: A, vol. 593, pp. 170-177, 2014.

[36] Y. Li and D. Gu, "Parametric analysis of thermal behavior during selective laser melting additive manufacturing of aluminum alloy powder," Materials and Design, vol. 63, pp. 856-867, November 2014.

[37] L. Parry, I. Ashcroft, and R. D. Wildman, "Understanding the effect of laser scan strategy on residual stress in selective laser melting through thermo-mechanical simulation," Additive Manufacturing, vol. 12, pp. 1-15, 2016.

[38] Y. Li and D. Gu, "Parametric analysis of thermal behavior during selective laser melting additive manufacturing of aluminum alloy powder," Materials $\mathcal{E}$ Design, vol. 63, pp. 856-867, 2014.

[39] T. Huber, H.-P. Degischer, G. Lefranc, and T. Schmitt, "Thermal expansion studies on aluminium-matrix composites with different reinforcement architecture of SiC particles," Composites Science and Technology, vol. 66, no. 13, pp. 22062217, 2006.

[40] Z. Xu, K. Chawla, R. Mitra, and M. Fine, "Effect of particle size on the thermal expansion of TiC/A1 XDTM Composites," Scr. Metall. Mater, vol. 31, pp. 15251530, 1994.

[41] X. Zhu, R. Wang, C. Peng, W. Liu, and J. Peng, "Microstructure and thermal expansion behavior of spray-formed Al-27Si alloy used for electronic packaging," Journal of Materials Science: Materials in Electronics, vol. 25, no. 11, pp. 48894895, 2014.

[42] Sandvik, "CE alloy products - alloys and properties." https://www.materials.sandvik/en/products/ce-alloys/product-properties/tabthermal-properties, visited: 29.01.2019. 